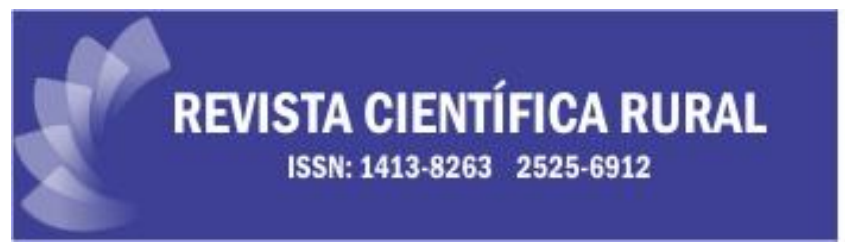

\title{
EFEITO DE DOSES DE NITROGÊNIO NO DESEMPENHO DA CULTURA DO RABANETE
}

\author{
Marcus Vinícius Gonçalves Lima', Bruno da Silva Santos², Mayara Pereira Coelho², Talyne Mendes \\ dos Santos ${ }^{2}$, Cristiane Mognon²
} 'Professor Doutor do curso de Agronomia da Universidade do Estado de Mato Grosso (UNEMAT), Campus Eugênio Carlos
Stieler, Tangará da Serra, Mato Grosso, Brasil. ²Acadêmico (a) do curso de Agronomia da Universidade do Estado de Mato
Grosso (UNEMAT), Campus Eugênio Carlos Stieler, Tangará da Serra, Mato Grosso.

RESUMO: A produção mundial de rabanete está estimada em sete milhões de toneladas por ano, desse modo, conhecer o desenvolvimento da cultura permite a maximização das áreas de produção agrícola. Objetivou-se com este trabalho avaliar a influência da adubação nitrogenada no desenvolvimento da cultura do rabanete. $O$ experimento foi realizado na cidade de Tangará da Serra - MT. Os canteiros receberam uma adubação com superfosfato simples e cloreto de potássio, já a adubação nitrogenada foi realizada utilizando ureia, parcelada em três aplicações, sendo $1 / 3$ no plantio, $1 / 3$ aos 7 dias após o plantio e os outros $1 / 3$ aos 14 dias após o plantio. $O$ delineamento experimental utilizado foi o de blocos casualizados, sendo cinco doses de $\mathrm{N}\left(0,40,80,120\right.$ e $\left.160 \mathrm{~kg} \mathrm{ha}^{-1}\right)$, com quatro repetições. Após 36 dias da semeadura foram colhidas cinco plantas centrais de cada canteiro e foram determinadas: altura da planta, diâmetro de raízes, matéria fresca da parte aérea, raiz e total e matéria seca da parte aérea, raiz e total. Foi observado diferença significativa para todas as variáveis analisadas. A aplicação de nitrogênio promove melhorias no desempenho da cultura do rabanete e a dose de $160 \mathrm{~kg} \mathrm{ha}^{-1}$ de $\mathrm{N}$ promove o máximo desempenho.

Palavras-chave: Raphanus sativus, adubação, ciclo curto, ureia

\section{EFFECT ON NITROGEN DOSES RABANETE CULTURE PERFORMANCE}

ABSTRACT: The world production of radish is estimated at seven million tons per year, that way, knowing the development of the crop allows the maximization of the agricultural production areas. The objective of this work was to evaluate the influence of nitrogen fertilization on the development of the radish culture. The experiment was carried out in the city of Tangará da Serra - MT. The beds received fertilization with simple superphosphate and potassium chloride, while nitrogen fertilization was carried out using urea, divided into three applications, 1/3 at planting, 1/3 at 7 days after 
planting and the other $1 / 3$ at 14 days after planting. The experimental design used was randomized blocks, with five doses of $N\left(0,40,80,120\right.$ and $\left.160 \mathrm{~kg} \mathrm{ha}^{-1}\right)$, with four replications. After 36 days of sowing, five central plants were harvested from each bed and determined: plant height, root diameter, fresh matter of aerial part, root, and total and dry matter of aerial part, root, and total. Significant difference was observed for all variables analyzed. The application of nitrogen promotes improvements in the performance of the radish culture and the dose of $160 \mathrm{~kg} \mathrm{ha}^{-1}$ of $\mathrm{N}$ promotes maximum performance.

Key words: Raphanus sativus, fertilization, short cycle, urea

\section{INTRODUÇÃO}

O rabanete (Raphanus sativus L.) é originário da região mediterrânea e pertence à família das Brassicaceaes, sendo uma das hortaliças de mais antigo cultivo (CAETANO et al., 2015), é uma cultura de ciclo curto, raízes globulares de casca com coloração avermelhada e polpa branca, tais raízes apresentam um sabor peculiar picante (MAIA et al., 2011), seu consumo se dá principalmente na forma de saladas e conservas (SILVA et al., 2012).

A produção mundial de rabanete está estimada em sete milhões de toneladas por ano, sendo o Japão um dos grandes produtores (ITO; HORIE, 2008). A produção brasileira de rabanete está estimada em nove mil toneladas, cultivadas em aproximadamente seis mil estabelecimentos agropecuários, sendo a produção concentrada nas regiões sul e sudeste (IBGE, 2019). Já, a comercialização de sementes no Brasil gira em torno de $15,5 \mathrm{t} \mathrm{ano}^{-1}$, sendo cultivados 1.107 ha ano-1 (ABCSEM, 2010).

Por ser uma cultura de ciclo curto, possibilita o consórcio com outras olerícolas que exigem maior espaçamento, além disso, pode ser cultivada em vasos onde o espaço de cultivo é limitado (CAETANO et al., 2015). Durante seu desenvolvimento é formado uma grande quantidade de massa em sua raiz globuosa, para isso requer elevada quantidade de nutrientes (OLIVEIRA et al., 2014), sendo o nitrogênio (N) e potássio requeridos em maior quantidade para a formação da raiz (ISLAM et al., 2011).

De acordo com Castro et al. (2016) o N é componente essencial de ácidos nucléicos, proteínas e aminoácidos, hormonas e clorofila, porém sua aplicação pode ser afetada pela perda do nutriente no solo principalmente com a fonte ureia devido à 
alta higroscopicidade e maior suscetibilidade a perda por volatilização quando aplicado em cobertura no solo.

Estudos avaliando a aplicação de fertilizantes sugeriram que a cultura do rabanete responde positivamente a doses crescentes de adubos nitrogenados (JILANI et al., 2010; BALOCH et al., 2014). Entretanto, ainda existe escassez de estudos em relação ao manejo da adubação na cultura, faltam estudos relacionados com a nutrição e resposta do rabanete à aplicação de diferentes fertilizantes ou diferentes doses desses fertilizantes (RODRIGUES et al., 2013).

Segundo Pedó et al. (2014) o conhecimento sobre os fatores relacionados ao crescimento e desenvolvimento das plantas permite o planejamento adequado para cada cultura, isso maximiza a utilização da área de produção visando maior produtividade, embora o rabanete seja importante economicamente em áreas urbanas e em áreas que rodeiam as cidades (periurbanas) por permitir a diversificação da produção, pesquisas envolvendo seu desenvolvimento e relacionadas a diferentes doses ou fontes de nitrogênio ao longo da sua ontogenia são escassas. Deste modo, objetivou-se com este trabalho avaliar a influência da adubação nitrogenada na produção de rabanete.

\section{MATERIAL E MÉTODOS}

O experimento foi realizado no campo experimental da Universidade do Estado de Mato Grosso (UNEMAT), situado na cidade de Tangará da Serra - MT (Latitude $14^{\circ} 37^{\prime} 10^{\prime \prime}$, Longitude $57^{\circ} 29^{\prime} 09^{\prime \prime}$ e altitude $440 \mathrm{~m}$ ).

A distribuição das chuvas na região apresenta variabilidade temporal anual de 2.861, 1.404 e 1.830 mm, para a máxima, mínima e média, respectivamente. A região apresenta duas estações definidas, uma estação seca de maio a setembro e outra chuvosa de outubro a abril (DALLACORT et al., 2011). De acordo com a classificação de Köppen o clima é Aw (HENTZ et al., 2016), com temperatura de 31.8, 21.1, 24.9 ${ }^{\circ} \mathrm{C}$, para a máxima, mínima e média, respectivamente.

Uma amostra do solo foi colhida na área do ensaio, na profundidade de 0 a 20 cm para caracterização química. O solo foi descrito como Latossolo Vermelho Argiloso de textura argilosa e de relevo plano à levemente ondulado (EMBRAPA, 2018). As características químicas do solo da área experimental foram determinadas antes da 
instalação do experimento, segundo metodologia proposta por Ribeiro et al. (1999), os resultados estão expostos na tabela 1.

\begin{tabular}{|c|c|c|c|c|c|c|c|}
\hline $\mathrm{pH}\left(\mathrm{CaCl}_{2}\right)$ & $\mathrm{P}$ & $\mathrm{K}$ & $\mathrm{Ca}^{2+}$ & $\mathrm{Mg}^{2+}$ & $\mathrm{H}+\mathrm{Al}$ & $\mathrm{V}$ & $\mathrm{MO}$ \\
\hline & --- & -3------- & ------. & $\mathrm{IOl}_{\mathrm{c}} \mathrm{dm}^{-}$ & ---- & $\%$ & $\mathrm{~g} \mathrm{~kg}^{-1}$ \\
\hline 6,2 & 36 & 90 & 3,5 & 0,8 & 2,29 & 68 & 19,2 \\
\hline
\end{tabular}

Com base nos resultados encontrados na análise de solo, os canteiros receberam uma adubação com cloreto de potássio e superfosfato simples, já a adubação nitrogenada foi aplicada na forma de ureia, parcelada em três aplicações, sendo $1 / 3$ no plantio, $1 / 3$ aos 7 dias após o plantio e os outros $1 / 3$ aos 14 dias após o plantio.

O delineamento experimental utilizado foi o de blocos casualizados, sendo cinco doses de $\mathrm{N}\left(0,40,80,120\right.$ e $\left.160 \mathrm{~kg} \mathrm{ha}^{-1}\right)$, com quatro repetições. A cultivar do rabanete avaliada foi o 'Crimson Gigante', seu plantio foi realizado com espaçamento de 0,2 entre plantas e 0,2 m entre linhas (40 plantas por parcela).

As plantas foram irrigadas diariamente, por microaspersão, duas vezes por dia, até o momento da colheita, o volume de água para os turnos de rega foi calculado a partir da estimativa da evapotranspiração da cultura (ETc), utilizando-se o método do evaporímetro de Piche (BURIOL et al., 2001). Os manejos culturais realizados foram: desbaste das plantas aos sete dias após semeadura e o controle de plantas daninhas através de capina manual.

Aos 36 dias após a semeadura foi efetuado a colheita de cinco plantas centrais de cada canteiro, separadas em sacos de papel e levadas ao Laboratório de Solos da Universidade do Estado de Mato Grosso (UNEMAT). Foram avaliadas as seguintes variáveis:

Altura da planta $(\mathrm{ALT})(\mathrm{cm})$ : realizada com auxílio de uma régua gradual em cinco plantas de cada parcela.

Diâmetro de raíz (DIAM) (mm): realizada em cinco plantas de cada parcela, utilizando uma fita métrica. 
Massa fresca da parte área (MFPA) (g planta-1 $)$, massa fresca da raiz (MFR) (g planta $^{-1}$ ) e massa fresca total (MFT) ( p planta $\left.^{-1}\right)$ : realizada em cinco plantas de cada parcela e pesadas em balança analitica.

Massa seca da parte aérea (MSPA) ( planta $^{-1}$ ), massa seca da raiz (MSR) (g planta $^{-1}$ ) e massa seca total (MST) (g planta $\left.{ }^{-1}\right)$ : após pesagem na balança analitica as cinco plantas foram levadas para estufa de circulação de ar forçada com temperatura de $65^{\circ} \mathrm{C}$, por 72 horas $(\mathrm{g})$ e após tal período, foi novamente pesada na mesma balança.

Os dados foram inicialmente submetidos ao teste de normalidade e homogeneidade, em seguida procedeu-se à análise de variância e, havendo significância, foi realizado a análise de regressão. $O$ modelo significativo de maior ordem e coeficiente de correlação $\left(R^{2}\right)$ foi selecionado para expressar o comportamento. As análises estatísticas foram realizadas com auxílio do programa computacional Sisvar (FERREIRA, 2011).

\section{RESULTADOS}

Na Tabela 2 é apresentada a análise de variância do desempenho de rabanete em diferentes doses de nitrogênio. Foi observado diferença significativa $(p<0,01)$ para todas as variáveis analisada: altura da planta (ALT), diâmetro de raíz (DIAM), massa fresca da parte área (MFPA), massa fresca da raiz (MFR) e massa fresca total (MFT), massa seca da parte aérea (MSPA), massa seca da raiz (MSR) e massa seca total (MST).

Tabela 2 . Análise de variância do desempenho de rabanete cv. Crimson Gigante em diferentes doses de nitrogênio.

Table 2. Variance analysis of radish performance cv. Crimson Gigante in different doses of nitrogen.

\begin{tabular}{|c|c|c|c|c|c|c|c|c|c|}
\hline $\begin{array}{l}\text { Fonte de } \\
\text { Variação }\end{array}$ & $\mathrm{GL}$ & $\mathrm{ALT}$ & DIAM & MFPA & MFR & MFT & MSPA & MSR & MST \\
\hline Doses de $\mathrm{N}$ & 4 & 18,9267 & 11,0032 & 17,2164 & 56,9609 & 37,6181 & 9,0725 & 12,4367 & 13,2453 \\
\hline Bloco & 3 & 0,7472 & 0,3871 & 0,5407 & 5,5025 & 2,7225 & 0,4045 & 3,6005 & 1,8760 \\
\hline Reg. Lineal & 1 & $56,74^{\star \star}$ & $38,00^{* *}$ & $54,53^{\star \star}$ & $201,02^{* *}$ & $146,99 * *$ & $27,42^{\star *}$ & $48,47^{\star \star}$ & $47,54^{\star \star}$ \\
\hline Reg. Quadrática & 1 & $5,20^{*}$ & $0,02^{\text {ns }}$ & $2,96^{\mathrm{ns}}$ & $0,17^{\mathrm{ns}}$ & $0,66^{\text {ns }}$ & $0,52^{\mathrm{ns}}$ & $0,24^{\mathrm{ns}}$ & $0,04^{\mathrm{ns}}$ \\
\hline Reg. Cúbica & 1 & $2,18^{\text {ns }}$ & $0,09^{n s}$ & $7,83^{*}$ & $2,93^{\text {ns }}$ & $0,58^{\text {ns }}$ & $2,90^{\mathrm{ns}}$ & $0,65^{\text {ns }}$ & $2,21^{\mathrm{ns}}$ \\
\hline CV (\%) & - & 6,46 & 7,20 & 11,69 & 9,24 & 9,08 & 14,26 & 16,48 & 13,25 \\
\hline Média & & 19,91 & 42,02 & 49,37 & 55,99 & 105,36 & 5,12 & 3,66 & 8,78 \\
\hline
\end{tabular}

${ }^{\star \star}$ Significativo $(\mathrm{p}<0,01)$ pelo teste F de probabilidade. Graus de Liberdade - GL; Coeficiente de variação - CV; Altura de planta - ALT; Diâmetro de raízes - DIAM; Massa fresca da parte aérea - MFPA; Massa fresca de raiz - MFR; Massa fresca total MFT; Massa seca da parte aérea - MSPA; Massa seca da raiz - MSR; Massa seca total - MST. 
O modelo de regressão que melhor se ajustou aos valores de altura de planta (ALT) de rabanete em função da adubação com diferentes doses de nitrogênio foi o linear crescente (Figura 1). De acordo com o modelo, estimou-se que o maior valor de $\operatorname{ALT}(22,15 \mathrm{~cm})$ foi encontrado com a dose $160,0 \mathrm{~kg}^{\mathrm{de}} \mathrm{N} \mathrm{ha}^{-1}$, sendo que essa dose proporcionou um incremento de $5,52 \mathrm{~cm}$, este valor equivale a $33,19 \%$ da ALT quando comparado com ausência de $\mathrm{N}$.

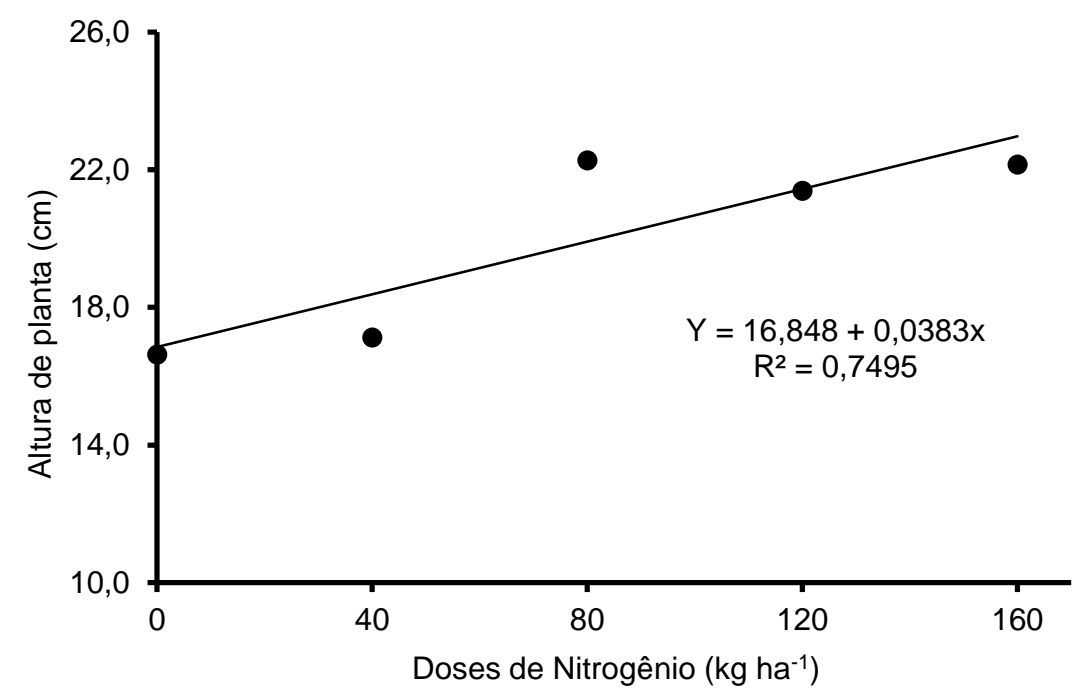

Figura 1. Altura de planta de rabanete cv. Crimson Gigante em diferentes doses de nitrogênio. Figure 1. Height of radish cv. Crimson Gigante in different nitrogen doses.

O modelo de regressão que melhor se ajustou aos valores de diametro de raíz (DIAM) de rabanete em função da adubação com diferentes doses de nitrogênio foi o linear crescente (Figura 2). De acordo com o modelo, estimou-se que o maior valor de DIAM $\left(49,25 \mathrm{~mm}\right.$ ) foi encontrado com a dose $160,0 \mathrm{~kg}$ de $\mathrm{N} \mathrm{ha}^{-1}$, sendo que essa dose proporcionou um incremento de $14,12 \mathrm{~mm}$, este valor equivale a $40,19 \%$ do DIAM quando comparado com ausência de $\mathrm{N}$. 


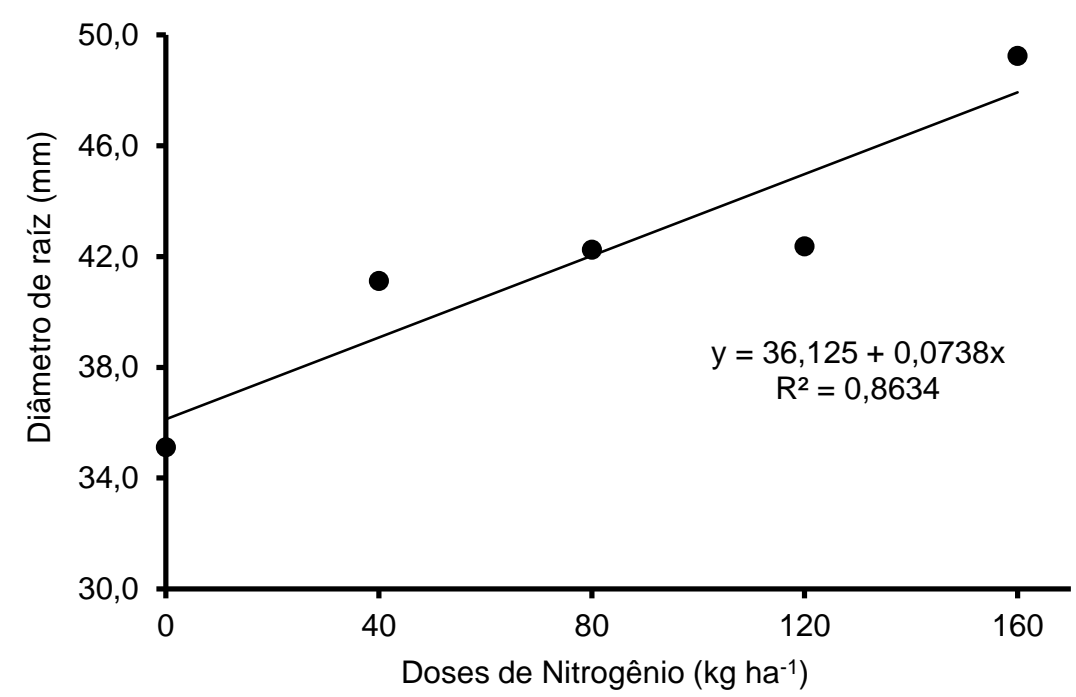

Figura 2. Diâmetro de raíz de rabanete cv. Crimson Gigante em diferentes doses de nitrogênio.

Figure 2. Radish root diameter cv. Crimson Gigante in different nitrogen doses.

O modelo de regressão que melhor se ajustou aos valores de massa fresca da parte aérea (MFPA) de rabanete em função da adubação com diferentes doses de nitrogênio foi o linear crescente (Figura 3). De acordo com o modelo, estimou-se que o maior valor de MFPA $(68,70 \mathrm{~g})$ foi encontrado com a dose $160,0 \mathrm{~kg}$ de $\mathrm{N} \mathrm{ha}^{-1}$, sendo que essa dose proporcionou um incremento de $32,05 \mathrm{~g}$, este valor equivale a $87,45 \%$ do MFPA quando comparado com ausência de N.

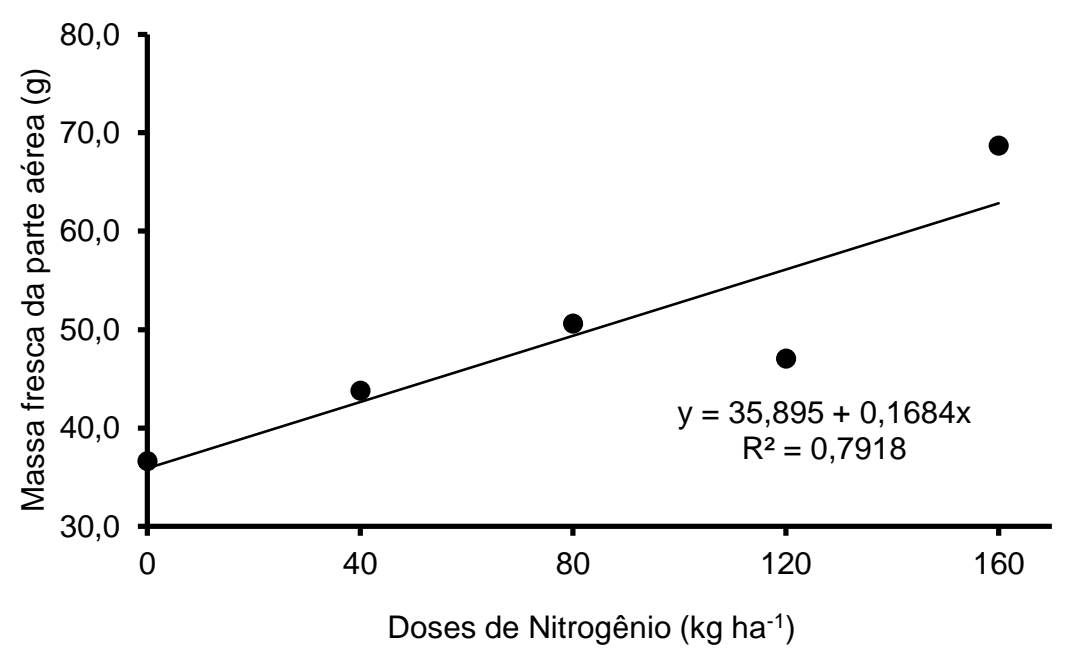

Figura 3. Massa fresca da parte aérea de rabanete cv. Crimson Gigante em diferentes doses de nitrogênio. Figure 3. Fresh mass of radish shoot cv. Crimson Gigante in different nitrogen doses.

O modelo de regressão que melhor se ajustou aos valores de massa fresca da raiz (MFR) de rabanete em função da adubação com diferentes doses de nitrogênio foi o linear crescente (Figura 4). De acordo com o modelo, estimou-se que o maior 
valor de MFR (75,71 g) foi encontrado com a dose $160,0 \mathrm{~kg} \mathrm{de} \mathrm{N} \mathrm{ha-1}^{-1}$, proporcionando um incremento de $43,66 \mathrm{~g}$, este valor equivale a $135,93 \%$ do MFR quando comparado com ausência de $\mathrm{N}$.

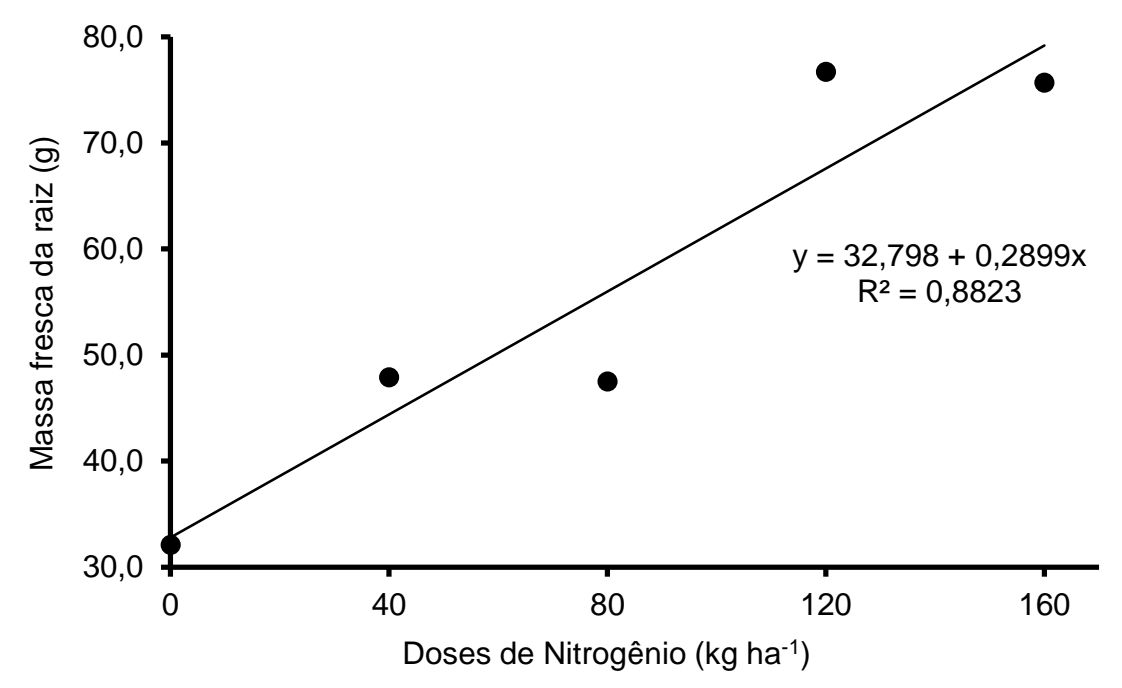

Figura 4. Massa fresca da raiz de rabanete cv. Crimson Gigante em diferentes doses de nitrogênio. Figure 4. Fresh radish root mass cv. Crimson Gigante in different nitrogen doses.

O modelo de regressão que melhor se ajustou aos valores de massa fresca total (MFT) de rabanete em função da adubação com diferentes doses de nitrogênio foi o linear crescente (Figura 5). De acordo com o modelo, estimou-se que o maior valor de MFT $(144,40 \mathrm{~g})$ foi encontrado com a dose $160,0 \mathrm{~kg}$ de $\mathrm{N} \mathrm{ha}^{-1}$, proporcionando um incremento de $75,71 \mathrm{~g}$, este valor equivale a $110,22 \%$ do MFT quando comparado com ausência de $\mathrm{N}$. 


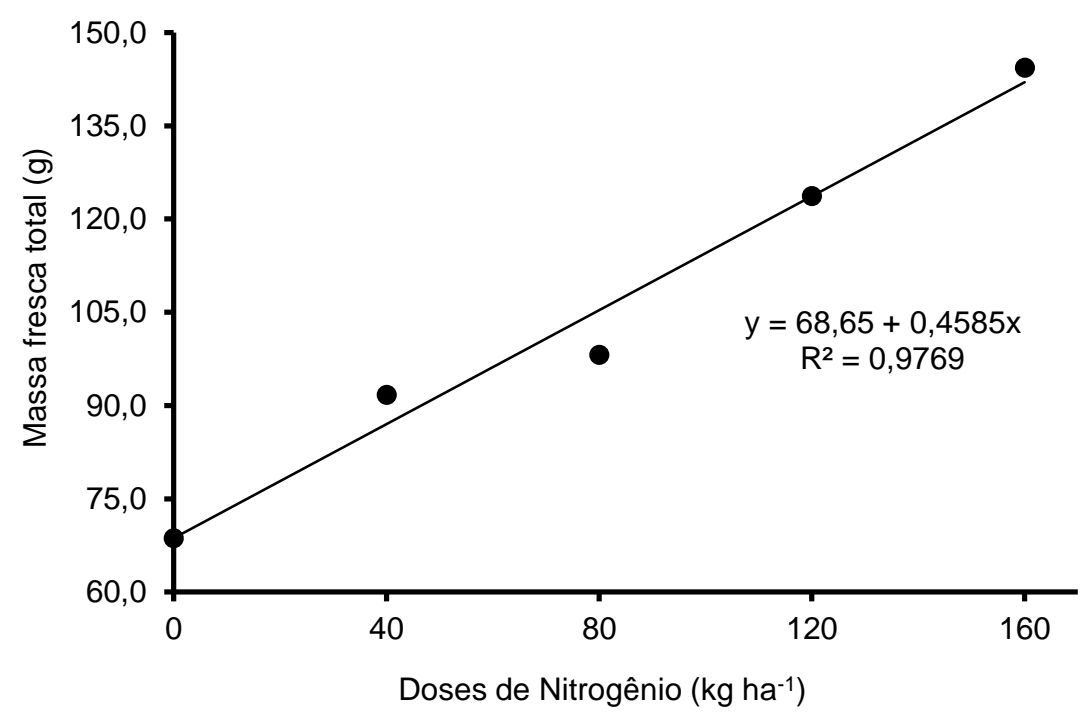

Figura 5. Massa fresca total de rabanete cv. Crimson Gigante em diferentes doses de nitrogênio.

Figure 5. Total fresh mass of radish cv. Crimson Gigante in different nitrogen doses.

O modelo de regressão que melhor se ajustou aos valores de massa seca da parte aérea (MSPA) de rabanete em função da adubação com diferentes doses de nitrogênio foi o linear crescente (Figura 6). De acordo com o modelo, estimou-se que o maior valor de MSPA (6,77 g) foi encontrado com a dose 160,0 kg de $\mathrm{N} \mathrm{ha}{ }^{-1}$, proporcionando um incremento de $2,81 \mathrm{~g}$, valor este que equivale a $70,96 \%$ do MSPA quando comparado com ausência de $\mathrm{N}$.

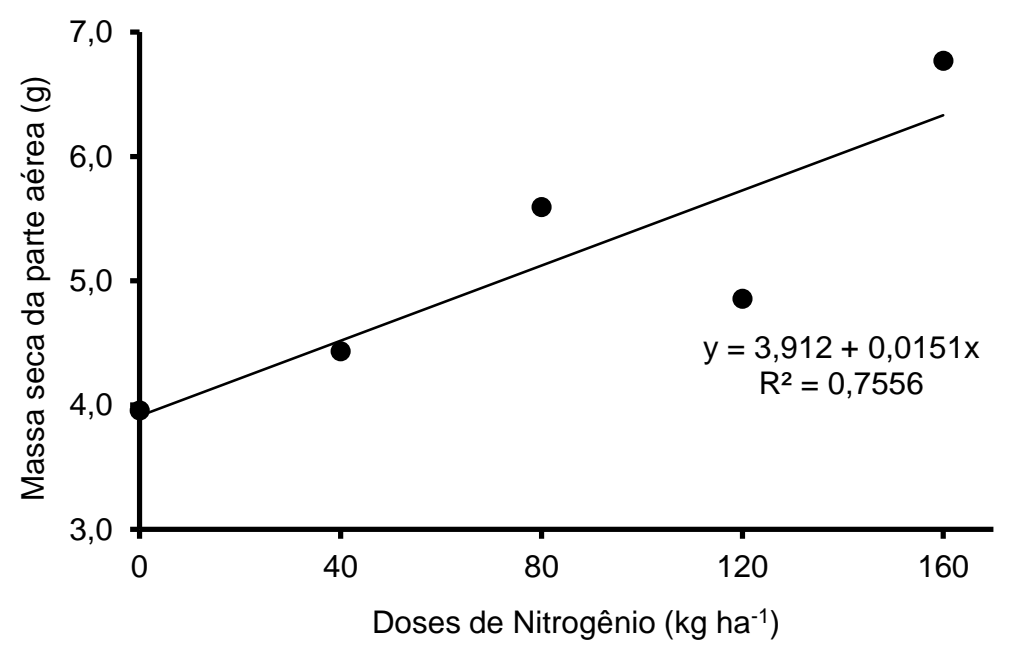

Figura 6. Massa seca da parte aérea de rabanete cv. Crimson Gigante em diferentes doses de nitrogênio. Figure 6. Dry mass of radish cv. Crimson Gigante in different doses of nitrogen.

O modelo de regressão que melhor se ajustou aos valores de massa seca da raiz (MSR) de rabanete em função da adubação com diferentes doses de nitrogênio 
foi o linear crescente (Figura 7). De acordo com o modelo, estimou-se que o maior valor de MSR $(5,01 \mathrm{~g})$ foi encontrado com a dose $160,0 \mathrm{~kg}$ de $\mathrm{N} \mathrm{ha}^{-1}$, proporcionando um incremento de $2,81 \mathrm{~g}$, valor este que equivale a $127,73 \%$ do MSR quando comparado com ausência de $\mathrm{N}$.

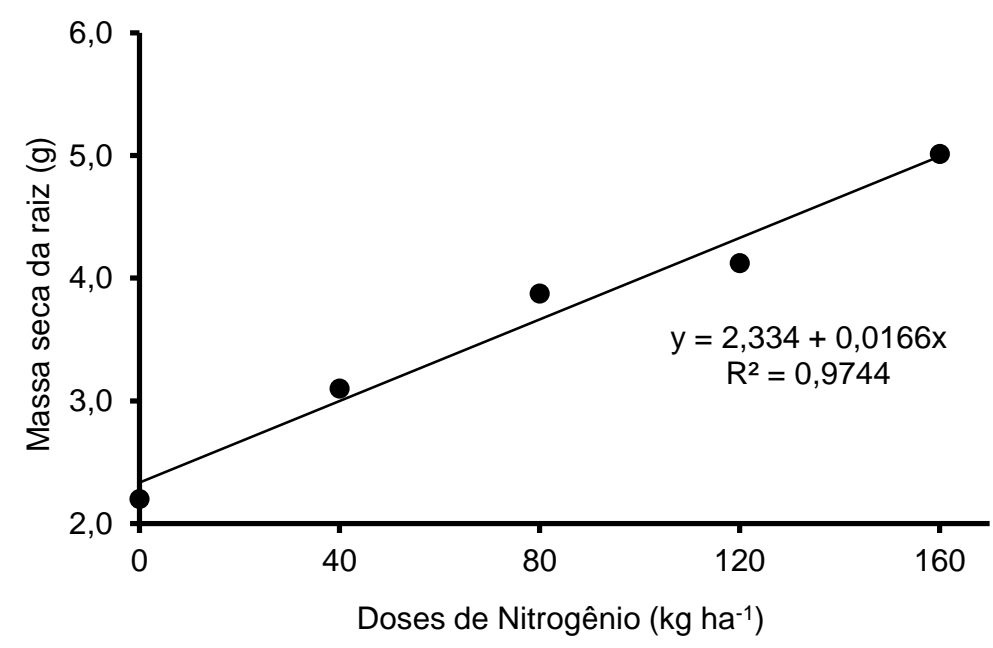

Figura 7. Massa seca da raiz de rabanete cv. Crimson Gigante em diferentes doses de nitrogênio. Figure 7. Dry radish root mass cv. Crimson Gigante in different nitrogen doses.

O modelo de regressão que melhor se ajustou aos valores de massa seca total (MST) de rabanete em função da adubação com diferentes doses de nitrogênio foi o linear crescente (Figura 8). De acordo com este modelo de regressão, estimou-se que o maior valor de MST $(11,78 \mathrm{~g})$ foi encontrado com a dose $160,0 \mathrm{~kg}$ de $\mathrm{N} \mathrm{ha}^{-1}$, sendo que essa dose proporciona um incremento de $5,62 \mathrm{~g}$, valor este que equivale a $91,23 \%$ do MST quando comparado com ausência de N.

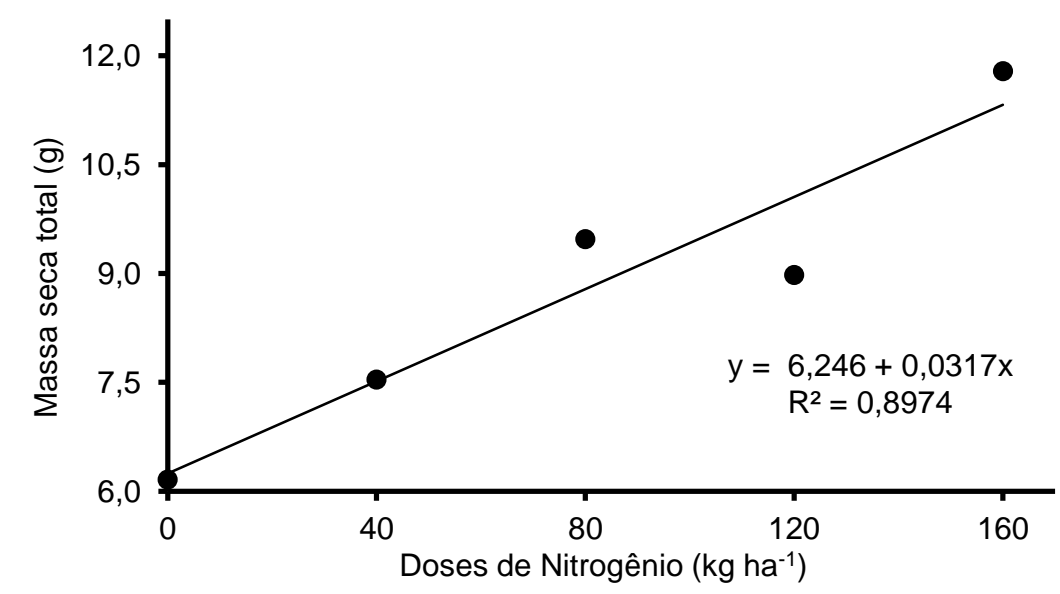

Figura 8. Massa seca total de rabanete cv. Crimson Gigante em diferentes doses de nitrogênio. Figure 8 . Total dry mass radish cv. Crimson Gigante in different nitrogen doses. 


\section{DISCUSSÃO}

O nitrogênio é um macronutriente absorvido preferencialmente na forma de nitrato ou amônio e é considerado elemento essencial para as plantas por ser requerido em grandes quantidades e fazer parte da constituição de aminoácidos, proteínas e enzimas (ANDRIOLO, 2000), isto pode ser confirmado com os resultados encontrados neste trabalho, doses de $160 \mathrm{~kg} \mathrm{ha}^{-1}$ de nitrogênio, mostraram-se eficientes no desenvolvimento da cultura do rabanete para todas as variáveis avaliadas.

O nitrogênio desempenha papel fundamental do desenvolvimento de hortaliças pois é componente de inúmeros compostos na planta, exercendo efeito no desenvolvimento da planta, consequentemente, sua falta afeta de forma considerável o potencial produtivo da cultura (MALAVOLTA, 2006).

Colaborando com os resultados encontrados neste trabalho, Sharma; Lal (1991) verificaram que o crescimento vegetativo, tal como a altura, número de ramos primário, secundário e terciário/planta e diâmetro das raízes de rabanete foram positivamente afetados devido à aplicação de doses de $\mathrm{N}$ até $150 \mathrm{~kg} \mathrm{ha}^{-1}$ de $\mathrm{N}$.

Dantas Junior et al. (2014) verificaram que o aumento da dose de nitrogênio incrementou o diâmetro comercial, sendo $38 \mathrm{~mm}$ o máximo valor observado. Oliveira et al. (2014), encontraram resultados semelhantes. O trabalho desenvolvido por Dantas Junior et al. com a mesma cultivar de rabanete (Crimson Gigante), verificaram que a aplicação de $120 \mathrm{~kg}$ de $\mathrm{N} \mathrm{ha}^{-1}$ proporcionou o maior diâmetro de raiz $(37,7 \mathrm{~mm})$. Esses valores são inferiores aos encontrados neste trabalho, entretanto, Castro et al. (2016) encontrou valores próximos aos encontrados neste trabalho (47, $5 \mathrm{~mm})$.

Chapin (1980) afirma que o nitrogênio é o elemento que mais limita o crescimento vegetal, e sua baixa disponibilidade foi associada à redução da divisão e expansão celular, da área foliar e da fotossíntese.

Pedó et al. (2014) avaliando o crescimento de rabanete em função da adubação com $\mathrm{N}$ observaram que dose de $15 \mathrm{~kg} \mathrm{ha}^{-1}$ proporcionou melhores características de crescimento às plantas.

O nitrogênio é componente da clorofila, aminoácidos, proteínas, nucleotídeos e outros compostos importantes no metabolismo das plantas. Sua ausência bloqueia a síntese de citocinina, hormônio responsável pelo crescimento das plantas, causando 
redução do tamanho e consequentemente redução da produção econômica das sementes. A escassez ou o excesso de nitrogênio pode causar estresse nutricional afetando o processo metabólico dos vegetais (MARSCHNER, 2012).

El-Desuki et al. (2005) trabalhando com a cultura do rabanete obtiveram massa

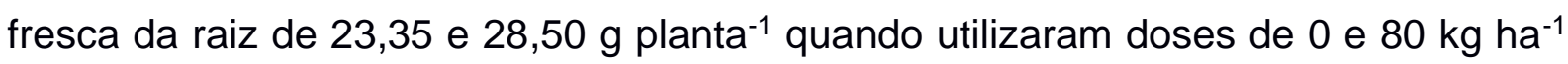
de N. Esses valores foram inferiores ao obtidos neste trabalho. O nitrogênio é um nutriente requerido em grandes quantidades pelas hortaliças (FILGUEIRA, 2008), desempenha papel fundamental no crescimento e no rendimento dos produtos colhidos (OLIVEIRA et al., 2006).

Caetano et al. (2015) trabalhando a mesma cultivar e doses idênticas as usadas neste trabalho no município de Urutaí - GO, não observaram diferença significativa para altura de plantas, diâmetro de raízes, massa fresca da parte aérea e raiz e massa seca da parte aérea e raiz.

El-Desuki et al. (2005) observaram que a adição de $\mathrm{N}$ aumentou significativamente a massa seca da parte área das plantas de rabanete, entretanto, Bulegon et al. (2012) constataram que a massa fresca e seca de raízes não foram influenciadas pelas diferentes doses de $\mathrm{N}$.

Bulegon et al. (2012) avaliando a massa seca de parte aérea e de raízes da cultura do rabanete submetida a doses de nitrogênio e deposição de palhada de feijão de porco em Marechal Cândido Rondon - PR não obtiveram diferença para essas variáveis, resultados semelhantes aos encontrados por Ferreira et al. (2011).

Santos et al. (2017) avaliaram o crescimento de rabanete submetido a doses crescentes de nitrogênio $\left(0 ; 30 ; 60 ; 90 ; 120\right.$; e $\left.150 \mathrm{~kg} \mathrm{ha}^{-1}\right)$, via fertirrigação, não verificaram diferença na produção de raiz de rabanete.

Pedó et al. (2014) afirmaram que as fertilizações nitrogenadas proporcionaram menores razões de massa da parte aérea, indicando que menor quantidade de massa seca foi alocada na parte aérea e maior quantidade translocada e alocada nas raízes. Afirmaram ainda que a dose de $15 \mathrm{~kg} \mathrm{ha}^{-1}$ proporcionou melhores características de crescimento às plantas de rabanete.

Em várias hortaliças, o nitrogênio desempenha papel fundamental no crescimento e no rendimento dos produtos colhidos (OLIVEIRA et al., 2006). Coutinho Neto et al. (2010) também verificaram que a adubação nitrogenada promoveu 
incremento significativo na produção de massa seca e nas concentrações de $\mathrm{N}$ e K na parte aérea das plantas.

\section{CONCLUSÕES}

A aplicação de nitrogênio apresenta efeito no desempenho da cultura do rabanete e a dose de $160 \mathrm{~kg} \mathrm{ha}^{-1}$ de $\mathrm{N}$ promove o máximo desempenho vegetativo, nas condições do presente estudo.

\section{REFERÊNCIAS}

ABCSEM (ASSOCIAÇÃO BRASILEIRA DO COMÉRCIO DE SEMENTES E MUDAS). Manual técnico: cultivo de hortaliças. 3.ed. Campinas, 2015. 100p.

ANDRIOLO, J. L. Fisiologia da produção de hortaliças em ambiente protegido. Horticultura Brasileira, v.18, p.26-33, 2000. Suplemento.

BALOCH, P. A.; UDDIN, R.; NIZAMANI, F. K.; SOLANGI, A. H.; SIDDIQUI, A. A. Effect of Nitrogen, Phosphorus and Potassium Fertilizers on Growth and Yield Characteristics of Radish (Raphinus sativus L.). American-Eurasian Journal of Agricultural \& Environmental Sciences, v.14, n.6, p.565-569, 2014.

DOI: $\underline{10.5829 / \text { idosi.aejaes.2014.14.06.12350 }}$

BULEGON, L. G.; FERREIRA, S. D.; YASSUE, R. M.; MOREIRA, G. C.; PASTÓRIO, M. A.; FARIAS, F. B. Desenvolvimento e produtividade de rabanete sobre diferentes deposições de palhada de feijão de porco e doses de nitrogênio. Cultivando o Saber, v.5, n.4, p.191-202, 2012.

BURIOL, G. A.; LUZZA, J.; HELDWEIN, A. B.; STRECK, N. A. Evaporação d'água em estufas plásticas e sua relação com o ambiente externo: 1 - avaliação com o uso do tanque classe A e do evaporímetro de Piche. Revista Brasileira de Agrometeorologia, v.9, n.1, p.35-41, 2001.

CAETANO, A. O.; DINIZ, R. L. C.; BENETT, C. G. S.; SALOMÃO, L. C. Efeito de fontes e doses de nitrogênio na cultura do rabanete. Revista de Agricultura Neotropical, v.2, n.4, p.55-59, 2015. DOI: https://doi.org/10.32404/rean.v2i4.286

CASTRO, B. F. SANTOS, L G.; BRITO, C. F. B.; FONSECA, V. A.; BEBÉ, F. V. Produção de rabanete em função da adubação potássica e com diferentes fontes de nitrogênio. Revista de Ciências Agrárias, v.39, n.3, p.341-348, 2016. DOI: http://dx.doi.org/10.19084/RCA15131

CHAPIN, F. S. III. The mineral nutrition of wild plants. Annual Review of Ecology and Systematics, v.11. n.1, p.233-260, 1980. 
COUTINHO NETO, A. M.; ORIOLI JÚNIOR, V.; CARDOSO, S. S.; COUTINHO, E. L. M. Produção de matéria seca e estado nutricional do rabanete em função da adubação nitrogenada e potássica. Revista Núcleos, v.7, n.2, p.105-114, 2010.

DOI: http://dx.doi.org/10.3738/nucleus.v7i2.349

DALLACORT, R.; MARTINS, J. A.; INOUE, M. H.; FREITAS, P. S. L.; COLETTI, A. J. Distribuição das chuvas no município de Tangará da Serra, médio norte do Estado de Mato Grosso, Brasil. Acta Scientiarum Agronomy, v.33, n.2, p.193-200, 2011. DOI: 10.4025/actasciagron.v33i2.5838

DANTAS JUNIOR, G. J.; SILVA, P. F.; MATOS, R. M.; BORGES, V. E.; NETO, J. D. Produção comercial de rabanete fertirrigado com nitrogênio em ambiente protegido. Revista Educação Agrícola Superior, v.29, n.2, p.97-102, 2014.

http://dx.doi.org/10.12722/0101-756X.v29n02a10

EL-DESUKI, M.; SALMAN, S.R.; EL-NEMR, M.A.; ABDEL-MAWGOUD, A.M.R. Effect of Plant Density and Nitrogen Application on the Growth, Yield and Quality of Radish (Raphanus sativus L.). Journal of Agronomy, v.4, n.3, p. 225-229, 2005. DOI: 10.3923/ja.2005.225.229

EMBRAPA. EMPRESA BRASILEIRA DE PESQUISA AGROPECUÁRIA. Centro Nacional de Pesquisa de Solos. Sistema brasileiro de classificação de solos. $5^{\circ}$ edição. Rio de Janeiro: Embrapa, 2018. 356p.

FERREIRA, R. L. F.; GALVÃO, R. O.; JUNIOR, E. B. M.; NETO, S. E. A.; NEGREIROS, J. R. S; PARMEJIANI, R. S. Produção orgânica de rabanete em plantio direto sobre cobertura morta e viva. Horticultura Brasileira, v.29, n.3, p.299-303, 2011. DOI: http://dx.doi.org/10.1590/S0102-05362011000300007.

FERREIRA, D. F. Sisvar: um sistema computacional de análise estatística. Ciência e Agrotecnologia , v.35, n.6, p.1039-42, 2011.

FILGUEIRA, F. A. R. Novo manual de olericultura: agrotecnologia moderna na produção e comercialização de hortaliças. 3. ed. Viçosa-MG: UFV, 2008. 421 p.

HENTZ, P.; CORREAA, J.C.; FONTANELI, R.S.; REBELATTO, A.; NICOLOSO, R.S.; SEMMELMANN, C.E.N. Poultry litter and pig slurry applications in an integrated croplivestock system. Revista Brasileira de Ciência do Solo, v.40, e0150072, p.1-12, 2016. DOI: 10.1590/18069657rbcs20150072

IBGE (INSTITUTO BRASILEIRO DE GEOGRAFIA E ESTATístICA). Censo agropecuário 2019. Rio de Janeiro: IBGE, 2019. Disponível em: https://sidra.ibge.gov.br/tabela/2856. Acesso em: 25 jun. 2020.

ITO, H.; HORIE, H. A. A. Chromatographic method for separating and identifying Intact 4-Methylthio-3-Butenyl Glucosinolate in Japanese Radish (Raphanus sativus L.). Japan Agricultural Research Quarterly, v.42, n.2, p.109-114, 2008. 
ISLAM, M. M. A.; KARIM, J. M. S.; JAHIRUDDIN, M.; MAJID, M.; MIAH, M. G.; AHMED, M. M.; HAKIM, M. A. Effects of organic manure and chemical fertilizers on crops in the radish-stem amaranth Indian spinach cropping pattern in homestead area. Australian Journal of Crop Science, v.5, n.11, p.1370-1378, 2011.

JILANI, M. S.; BURKI, T.; WASEEM, K. Effect of nitrogen on growth and yield of radish. Journal of Agricultural Research, v.48, n.2, p.219-225, 2010.

MAIA, P. M. E.; AROUCHA, E. M. M.; SILVA, O. M. P.; SILVA, R. C. P.; OLIVEIRA, F. A. Desenvolvimento e qualidade do rabanete sob diferentes fontes de potássio. Revista Verde de Agroecologia e Desenvolvimento Sustentável, v.6, n.1, p.148-153, 2011.

MARSCHNER, P. Marschner's mineral nutrititon of higher plants. 3ed. Academic Press, 2012. 649p.

OLIVEIRA, G. Q.; BISCARO, G. A.; MOTOMIYA, A. V. A.; JESUS, M. P.; FILHO, P. $S$. V. Aspectos produtivos do rabanete em função da adubação nitrogenada com e sem hidrogel. Journal of Agronomic Sciences, v.3, n.1, p.89-100, 2014.

OLIVEIRA, A. P.; MOURA, M. F.; NOGUEIRA, D. H.; CHAGAS, N. G.; BRAZ, M. S. S.; OLIVEIRA, M. R. T.; BARBOSA, J. A. Produção de raízes de batata-doce em função do uso de doses de $\mathrm{N}$ aplicadas no solo e via foliar. Horticultura Brasileira, v. 24, p.279282, 2006. DOI: http://dx.doi.org/10.1590/S0102-05362006000300002

PEDÓ, T.; AUMONDE, T. Z.; MARTINAZZO, E. G.; VILLELA, F. A.; LOPES, N. F.; MAUCH, C. R. Análise de crescimento de plantas de rabanete submetidas a doses de adubação nitrogenada. Bioscience Journal, v.30, n.1, p.1-7, 2014.

RODRIGUES, J. F.; REIS, J. M. R.; REIS, M. A. Utilização de estercos em substituição a adubação mineral na cultura do rabanete. Revista Trópica - Ciências Agrárias e Biológicas, v.7, n.2, p.160-168, 2013. DOI: http://dx.doi.org/10.0000/rtcab.v7i2.1110

SANTOS, C. F. B., PAIER, C. D., GOMES, M. D. S., BISCARO, G. A. Efeito da adubação nitrogenada na produção e qualidade de rabanetes via fertirrigação por gotejamento. Acta Iguazu, v.6, n.2, p.50-58, 2017.

SHARMA, S. K.; LAL, G. Effect of nitrogen fertilization, plant spacing and steckling size on certain morphological characters and seed yield in radish. Vegetable Science, v.18, p.82-87, 1991. DOI: 10.3923 / ja.2005.225.229

SILVA, L. F. O.; CAMPOS, K. A.; MORAIS, A. R.; COGO, F. D.; ZAMBON, C. R. Tamanho ótimo de parcela para experimentos com rabanetes. Revista Ceres, v.59, n.5, p.624-629, 2012. DOI: http://dx.doi.org/10.1590/S0034-737X2012000500007. 